\title{
An Anti-windup Algorithm for PID Controller of PMSM SVPWM Speed
}

\section{Control System}

\author{
Bingyang Luo ${ }^{1, a}$, Mengchao $\mathrm{Li}^{1, \mathrm{~b}}$, Ping Wang ${ }^{1, \mathrm{c}}$, Tianyuan $\mathrm{Yu}{ }^{1, \mathrm{~d}}$ \\ ${ }^{1}$ School of Automation, Wuhan University of technology, Wuhan, Hubei, 430070, China \\ a 442493007@qq.com, b 731977464@qq.com, c 672998650@qq.com, ${ }^{\text {d } 835826165 @ q q . c o m}$
}

Keywords: PMSM Speed Control System; PID control; Anti-windup; MATLAB \& simulation.

Abstract. PID controller is one of the most widely used in permanent magnet synchronous motor speed control system. Better control effect is to be obtained while applied in the speed-adjusted system for PMSM. To the problem of windup in the PID controller [1], this paper proposes an anti-saturation PID algorithm. The effectiveness is tested by using MATLAB\&Simulation. Using this new improved PID controller algorithm we can reduce the overshoot of the speed regulating system and shorten the stabilization time.

\section{Introductions}

The basic idea of PMSM control [2] comes from the ordinary three-phase AC motor to simulate DC motor speed control. In the PMSM SVPWM control, through the control of the stator current to improve performance of motor torque control, and the stator current is final control object. Under the three-phase static coordinate, the AC currents $i_{a}, i_{b}$, $i_{c}$ could be transformed to $i_{d}$, $i_{q}$ under synchronous rotating coordinate system by Clark and Park transformation. Meanwhile comparing the speed command signal and the rotor speed detection signal, after adjusting through the speed loop PID controller, output $i_{\text {dref, }}, i_{\text {qref }} . i_{q}$ and $i_{\text {qref }}, i_{d}$ and $i_{\text {dref }}$ were further compared with, and get through the current loop PID controller, we obtain the output axis voltage $V_{\text {dref }}$ and $V_{\text {qref }}$ under the d-q coordinate system. Again through the Park inverse transform, output vector voltage under $\alpha-\beta$ coordinate system, the three-phase inverter IGBT were drive by the six-channel PWM signal which were the output of the vector voltage through SVPWM module, to produce a continuous and variable frequency, amplitude three -phase sinusoidal current to input PMSM stator armature, thus completing the task of double closed loop vector control of PMSM [3].

PMSM vector control system consists of five parts: the position and speed detection, speed loop and current loop PI regulator, Clark and Park transformation, SVPWM space vector control modules.

\section{PID Control Theory}

As the most widely used controller, PID controller is used as speed loop and current loop controller in the PMSM speed control system which is simple, effective, and practical. Theory of PID control system shown in Fig.1, the system is mainly consists of PID controller and controlled object [4]. 


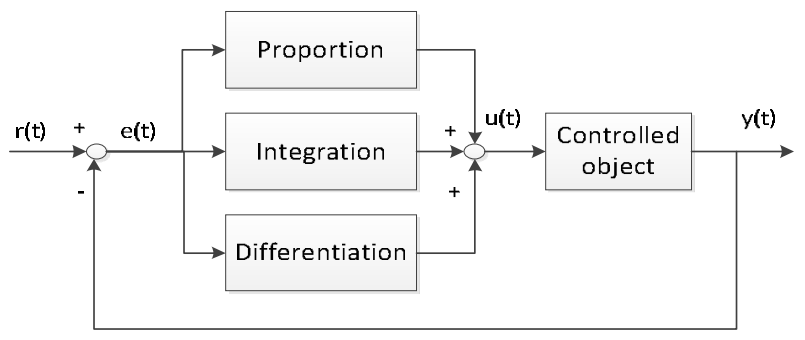

Fig.1 PID control system

PID controller is a kind of linear regulator, through proportionate, integrate and derivate the deviation of given value $r(t)$ and the actual output value $y(t)$, the linear combination of those three make up the control quantity to control the object.

2.1 The Function of Various Correction Link of PID Controller

Proportion: proportionately reaction to the deviation signal e $(\mathrm{t})$ of control system, once produced, controller will act immediately to minimize deviation.

Integration: it is mainly used to eliminate static error. The strength of the integral action depends on the integral time constant $r$, the bigger the $r$ to be, the weaker integral action is, and vice versa.

Differentiation: Reflect the change trend of deviation signal (rate of change), and before the deviation signal becomes too big, an effective early correction signal is leaded into system, thus accelerating the movement speed of system, reducing the adjusting time.

Traditional PID controller has two algorithms: Position and Incremental, after using DSP devices, typically using digital PID control analog PID control functions. PID controller equation is able to discrete computing.

\subsection{Position Digital PID Control Algorithm}

The differential equation of PID controller:

$\mathrm{u}(t)=K_{p}\left[e(t)+\frac{1}{T_{i}} \int_{0}^{t} e(t) d t+T_{d} \frac{d e(t)}{d t}\right]$

$\mathrm{Kp}$ is proportional gain; $\mathrm{Ti}$ is integral time constant; $\mathrm{u}(\mathrm{t})$ is output control quantity;

e $(\mathrm{t})$ is deviation; e $(\mathrm{t})=\mathrm{r}(\mathrm{t})-\mathrm{y}(\mathrm{t})$.

We can obtain the following approximate transformation:

$\int_{0}^{t} e(t) d t \approx T \sum_{0}^{k} e(i) \quad \frac{d e(t)}{d t} \approx \frac{e(k)-e(k-1)}{T}$

Then the differential equation of PID controller translates into:

$u(k)=K_{p} e(k)+K_{i} \sum_{0}^{k} e(i)+K_{d}[e(k)-e(k-1)]$

$K_{i}=K_{p} \cdot \frac{T}{T_{i}} ; K_{d}=K_{p} \bullet \frac{T_{d}}{T}$

Due to Position PID control algorithm is the total amount of output, so each outputs are related with the past state, $\mathrm{e}(\mathrm{k})$ has to accumulate when calculations, computing workload. Moreover, because the computer output $\mathrm{u}(\mathrm{k})$ corresponds to the actual position of the actuator, if the computer fails, a substantial change in $\mathrm{u}(\mathrm{k})$ will cause a substantial change in position of the actuator, may cause significant accidents, in order to avoid this situation, Incremental PID control algorithm is proposed

2.3 Incremental PID Control Algorithm

From the above analysis, differential equation of PID controller is: 


$$
\begin{aligned}
& u(k)=K_{p} e(k)+K_{i} \sum_{0}^{k} e(i)+K_{d}[e(k)-e(k-1)] \\
& u(k-1)=K_{p} e(k-1)+K_{i} \sum_{0}^{k-1} e(i)+K_{d}[e(k-1)-e(k-2)]
\end{aligned}
$$

Subtracting the above two equations:

$$
\begin{aligned}
& \Delta u(k)=u(k)-u(k-1)=K_{p}[e(k)-e(k-1)]+K_{i} e(k)+K_{d}[e(k)-2 e(k-1)+e(k-2)] \\
& K_{i}=K_{p} \cdot \frac{T}{T_{i}} ; K_{d}=K_{p} \cdot \frac{T_{d}}{T}
\end{aligned}
$$

\section{PID Controller Windup Phenomenon}

The so-called windup phenomenon refers to if the system exist a direction of deviation, due to the integral action the output of the PID controller accumulate and increase continuously, causing the actuator to the limit position; If the controller output $\mathrm{u}(\mathrm{k})$ is continues to increase, the opening degree of the actuator cannot be increased, then the control amount of computer output beyond the normal operating range and into the saturated zone. Once the system has a reverse bias, $\mathrm{u}(\mathrm{k})$ gradually withdraw from the saturated zone. The deeper the saturated zone get in, the longer to exit the saturated zone. During this period, the actuator remains at extreme position, without making the appropriate changes immediately when reverse bias exists, the system just like out of control at this time, resulting in deterioration of the control performance, which is called integral windup phenomenon or runaway phenomenon.

In the PMSM speed control system, when the speed deviation produce jump in a long time, the output of Position PID will dramatically increase. Once the output of system requires a long time to reaches a given value, during this time the integral term will produce a large accumulated value. When the output cumulative value exceeds the saturation values, the bias reverse, but due to the larger accumulation value of the integral, the control amount required considerable period of time to out of the saturated zone. Therefore, windup phenomenon will increase overshoot of the system, the system stabilization time becomes longer, even under certain conditions cause system instability, thereby greatly reducing the overall system performance.

In the traditional PID controller design process, the parameters of the PID controller tuning is in the linear region, ignoring the nonlinear factors caused by saturation, so the performance of traditional design PID controller will be worse than expected, in order to reduce the effects of saturation nonlinear factors on system performance, resulting in anti-saturation theory [5].

This paper presents an anti-saturation PID controller design method, in order to verify the correctness of theoretical analysis and effectiveness of this control method, we conducted MATLAB simulations. Experimental results show that the anti-windup PID controller can effectively reduce the overshoot of speed control system, shorten the settling time of the system and improve the ability of anti-system load disturbance.

\section{Anti-windup PID Controller Design}

Through theoretical analysis of the PID regulator shows that digital PID controller differential equation is:

$u(k)=K_{p}\left\{e(k)+\frac{T}{T_{i}} \sum_{0}^{k} e(i)+\frac{T_{d}}{T}[e(k)-e(k-1)]\right\}$

The PID controller in speed control system often using incremental PID control: 


$$
\begin{aligned}
& \Delta u(k)=u(k)-u(k-1)=K_{p}[e(k)-e(k-1)]+K_{i} e(k)+K_{d}[e(k)-2 e(k-1)+e(k-2)] \\
& K_{i}=K_{p} \cdot \frac{T}{T_{i}} ; K_{d}=K_{p} \cdot \frac{T_{d}}{T}
\end{aligned}
$$

Kth PID controller output $\mathrm{u}(\mathrm{k})$ can be expressed as:

$$
u(k)=\Delta u(k)+u(k-1)
$$

From the above equation classic incremental PID control algorithm needs to reserve the value of the first two moment's deviation.

In this paper, we target on the following three aspects to design anti-windup PID controller:

(1) Limit the PID regulator output

For the PID regulator, when the deviation input is large, the output value will be large, it is possible comes to output saturation, it is often necessary for the PID controller to limit output.

When $\mathrm{u}(\mathrm{k})>\mathrm{u}_{\max }$, assume $\mathrm{u}(\mathrm{k})= \pm \mathrm{u}_{\max }$

Simply limit the output, in normal operation, it is possible that we unable to eliminate residual error.

(2) Integration separation

$|\mathrm{e}(\mathrm{k})|>\mathrm{e}_{\mathrm{p}}$, thus deviation is large, use pure P control, and can inhibit integral saturate.

$|\mathrm{e}(\mathrm{k})| \leqslant \mathrm{e}_{\mathrm{p}}$, thus deviation is small, use PI control; the integral could eliminate the bias.

(3) Weaken the integral method when reach to the limit

When speed control system is actually running, classic incremental PID control algorithm needs to reserve the value of the first two moment's deviation. This method is in the calculation of $u(k)$, first judges whether the upper time amount of control $\mathrm{u}(\mathrm{k}-1)$ is beyond limit or not

If $\mathrm{u}(\mathrm{k}-1)>\mathrm{u}_{\mathrm{p}}$, only accumulate negative bias;

If $\mathrm{u}(\mathrm{k}-1) \leqslant \mathrm{u}_{\mathrm{p}}$, only accumulate positive bias;

This algorithm can avoid a long stay in saturation zone for control amount. Control program flow of digital PID controller shown in Figure 2.

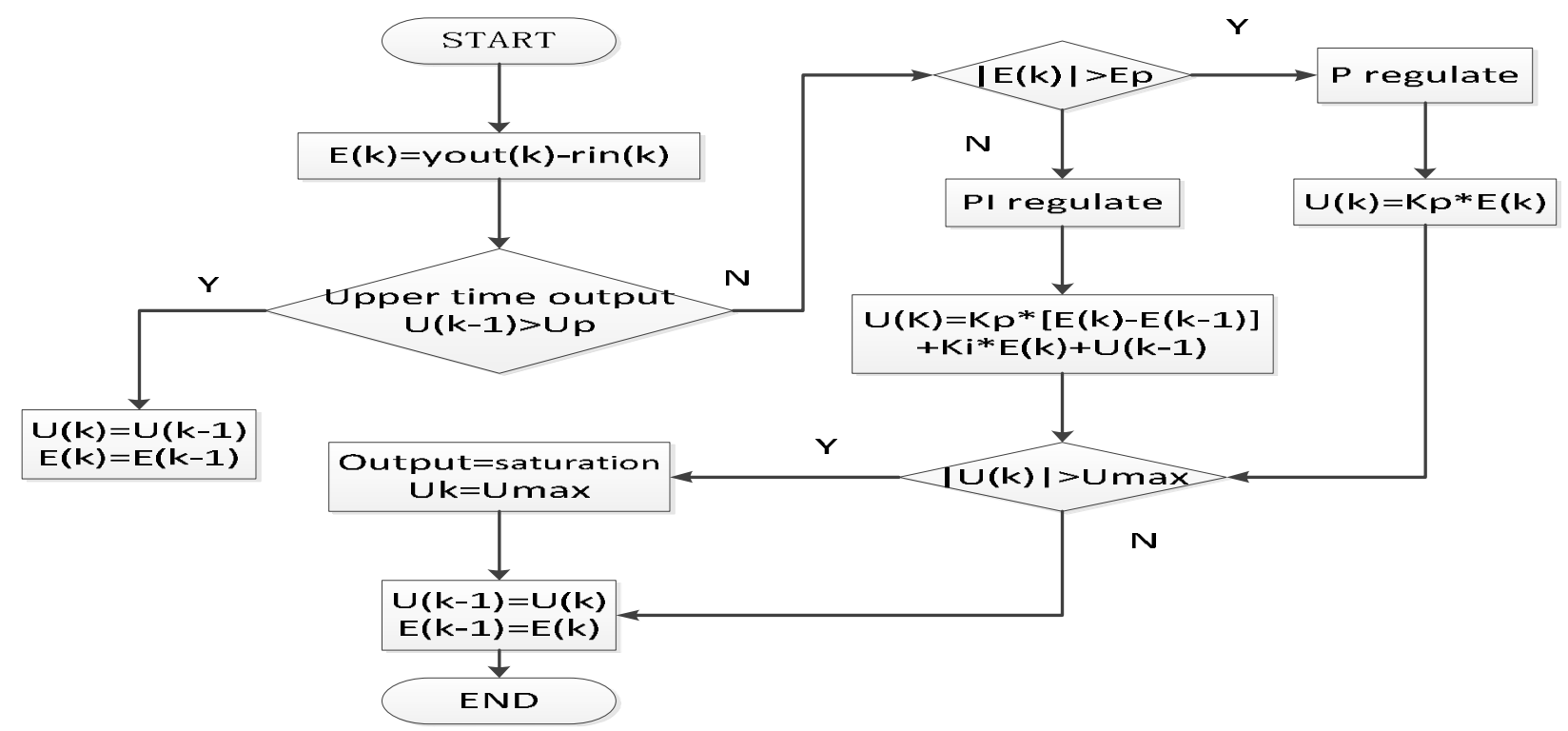

Fig.2 Control program flow of digital PID controller 


\section{MATLAB simulation and results analysis}

In order to verify the performance of anti-windup PID controller, we use

MATLAB software simulation [6], simulation given $3000 \mathrm{rpm} / \mathrm{min}$ speed step response, the sampling time is $1 \mathrm{~ms}$. Using anti-windup algorithm to dispersed systems step response simulation results shown in Figure 3. Using the traditional PID algorithm to dispersed system step response, the step response results shown in Figure 4. As can be seen from the simulation results, the use of anti-windup PID method can avoid a long stay in saturation zone for control amount, control the system overshoot.

Two kinds of PID algorithm with the same parameters, from the experimental waveforms we know, the improved PID algorithm rise time is $5.3 \times 10^{-3} \mathrm{~s}$, maximum overshoot is $45 \mathrm{rpm}$, the time to reach steady is $8.2 \times 10^{-3} \mathrm{~s}$; Traditional PID control algorithm rise time is $3.2 \times 10^{-3} \mathrm{~s}$, maximum overshoot is $440 \mathrm{rpm}$, and the time to reach steady is $0.017 \mathrm{~s}$. This shows that the overshoot and response time of improved anti-windup PID control algorithm both less than the traditional PID control algorithm, significantly improves the performance of the servo system.

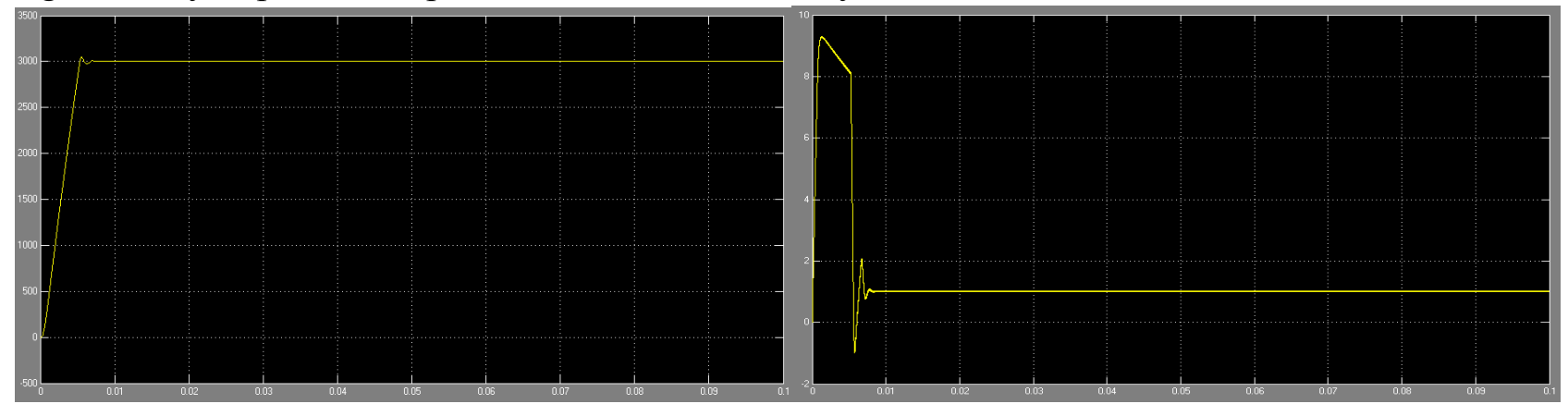

Fig.3 Improved PID control algorithm (left: n; right: Te)

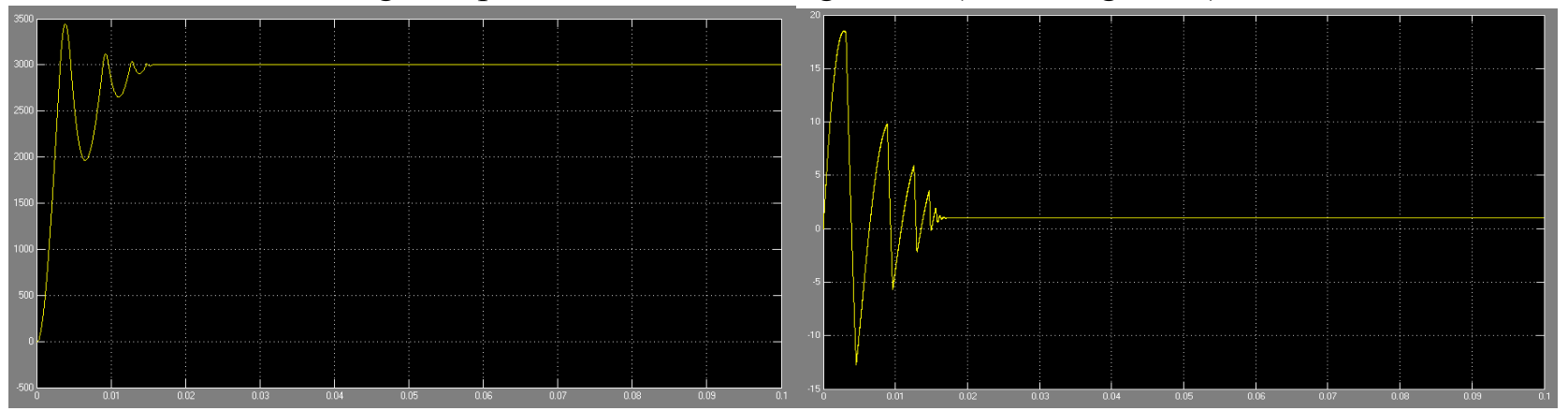

Fig.4 Traditional PID control algorithm (left: n; right: Te)

\section{Conclusion}

Traditional PID control algorithm ignores the nonlinear factors caused by saturation, so using traditional methods designed PID controller will get a worse performance than expected. Anti-windup function PID control algorithm proposed in this paper effectively suppresses windup; accelerate the speed of control system responsiveness. Theoretical analysis and experiments show that the algorithm can quickly follow the target speed, low the overshoot, and slight the concussion, also it remains the steady-state performance of traditional PID control algorithm.

The algorithm uses only a set of PID parameters, parameter tuning is more convenient, using the algorithm to the PMSM control system, can also meet the speed, low overshoot and other dynamic properties for driving the motor. 


\section{References}

[1] Boshi Chen. Electric drive automatic control system [M], Machinery Industry Press, 2005. In Chinese

[2] Renyuan Tang. Modern Theory and Design of Permanent Magnet Motor [M]. Peking: Machinery Industry Press, 1997. In Chinese

[3] TMS320C24x DSP Controllers Reference Set, Volume 2: Peripheral Library and Specific Devices [Z]. Texas Instruments, March, 1997

[4] Kyeong-Hwa Kim, Myung-Joong Youn.A nonlinear speed control for a PM synchronous motor using a simple disturbance estimation technique [J].IEEE Transactions on Industrial Electronics, 2002.49(3): 524-534.

[5] Ajith H, Wijenayake, Peter B. Schmidt. Modeling and Analysis of Permanent Magnet Synchronous Motor by Taking Saturation and Core Loss into Account: 1997 International Conference on Power Electronics and Drives Systems Proceedings, 1997.

[6] Jinkun Liu. MATLAB simulation of advanced PID control (Second Edition)[M].Peking: Electronic Industry Press,2004. In Chinese 